\title{
A COMPARATIVE ANALYSIS THROUGH TIME AND SPACE OF CENTRALITY'S ROLE IN COUNTY CENTERS' SPATIAL POSITION FOR SEVERAL COUNTIES IN ROMANIA
}

\author{
Zsolt MAGYARI-SÁSKA ${ }^{1}$
}

DOI : $10.21163 /$ GT_2019.142.05

\begin{abstract}
:
The aim of the study was to measure the importance of county centers in terms of central positioning and accessibility. The actual county centers have been chosen not only based on their central position but also based on other reasons such as their cultural, traditional and especially historical importance. With all these through time they should enforce their central position also in terms of accessibility - as some administration procedures can be managed just in these cities - and to became truly the centers of their counties. We want to check if the actual county centers fulfill these considerations, how strong is these fulfillments and in case of failure which cities could take their places. We also made some comparisons with former administrative organizations at the beginning of the $20^{\text {th }}$ century before car traffic appeared.
\end{abstract}

Key-words: network modeling, weighted network, closeness centrality, eigenvector centrality, ranking

\section{INTRODUCTION}

The actual county centers have been chosen not only based on their central position but also based on other reasons such as their cultural, traditional and especially historical importance. With all these through time they should enforce their central position also in terms of accessibility - as some administration procedures can be managed just in these cities - and to became truly the centers of their counties. Through history the border of middle level administrative entities has changed but in many cases the same cities remained as county centers for the newly created or modified administrative entities. Our research is focused on calculating and comparing the centrality of county centers by calculating those centrality indices which can be directly related to accessibility, considering the population movement too. In those cases, where the importance of a county center in terms of accessibility is not eloquent we try to show alternative locations and evaluate the whole county's accessibility if they would be county centers.

The comparison is made not just between different counties in present but also between two different time periods with different administrative borders, being 100 years apart from each other. The selected counties cover the major part of actual Transylvania, including Crișana but excepting the Banat region.

For characterizing the spatial accessibility there are many indicators, mainly connected to different centrality measures (Rodrigue, 2017; Miller, 2018). The importance of accessibility is present in many fields: city planning, emergency evaluation, touristic destination management or agriculture (Bilasco et all., 2018). The present research aim is to study the centrality of different settlements, especially the county centers, trying to prove that centrality was an important factor in tracing administrative borders. Various indices

\footnotetext{
${ }^{\text {I} B a b e s ̦-B o l y a i}$ University, Gheorgheni Extension, Gheorgheni, Romania, zsmagyari@gmail.com
} 
characterizing the centrality are defined for network models, considering the nodes' degree, the participation of a node in multiple path, the distance of a node form the other etc. (Bennison, 2010). Although, studies which evaluates the centrality of nodes, representing settlements or inner points of settlements are not new (Kang, 2015) these researches are part of a continuously developing mainstream not just by their results but also with their research methodology (Hellerik et all., 2019).

\section{METHODS AND DATA}

\subsection{Methods}

\subsubsection{Shape index}

The accessibility of polygons' centroid is undoubtedly related to the shape of the polygon. For a regular shape is much easy to have a high accessibility value than for an irregular or elongated shape having the same area. Through its shape every polygon holds a potential to have a higher or lower accessibility value for its centroid and also for its other points. This potential can be expressed by the shape index which is a ratio between the polygon perimeter and area. Through time were used several indices, but some of them were size dependent (Frohn, 1998; Lang \& Blaschke, 2007). The variant of the shape index that is scale independent is the ratio between the perimeter and the square root of area multiplied with $4 \pi$ (equation 1).

$$
s i=\frac{\text { perimeter }}{\sqrt{4 \pi \text { area }}}
$$

Its value is close to 1 in case of circular shapes and more distant for irregular and elongated shapes (Patton, 1975; Schumaker, 1996). In our case lower values will represent a higher centrality potential for a given county.

\subsubsection{Centrality}

The centrality of a node in a network can be measured in multiple ways. All of these try to determine how important is a node in a given network. Some of the most commonly used are (Bennison, 2010):

1) degree centrality, which considers that the most important node is that which has the most connections;

2) closeness centrality for which the most important node is that, which has the lowest average distance from all other nodes in the network;

3) betweenness centrality, which choses the most important node based on the number of shortest routes which are going through it.

Closeness centrality measures how distant is a given node form all other nodes in a network based on the shortest paths average distance (Sabidussi, 1996), (eq. 2).

$$
c c_{i}=\frac{\sum_{i, x \in G} d_{(i, x)}}{n-1}
$$

where $c c_{i}$ is the closeness centrality value for node $i, d_{(i, x)}$ is the length of shortest path between nodes $i$ and $x, n$ is the number of nodes in the connected graph $G$. The shortest path can be calculated in weighted and unweighted networks. The closeness centrality can be defined also for node weighted networks. In this case depending on application this 
weight can be a combination of node pair values for every shortest path or considering just one nodes' value. In our research as we were interested in studying the incoming population for a county center, we considered as node weight just the population of the incoming node. For shortest path calculation we used Dijkstra's algorithm, determining in one step all shortest routes from a given node (Dijkstra, 1959). A similar procedure was used by Nicoara \& Haidu (2014) in order to identify shortest route access to emergency medical facilities. All calculation concerning centrality values were made in an external application written in $\mathrm{C}++$.

Eigenvector centrality is an index which measures the importance of a node in a network (Negre et all., 2018; Hexmoore, 2015). This importance can be expressed as a selected weight assigned to every node of the network. The calculus of the eigenvector centrality starts from an arbitrary vector assigned to every node. In every step new eigenvector values are calculated as a product between their existing (old) values and the node's weight. After that the obtained vector is normalized by the highest value obtained in present step calculus. The number of steps is defined by a threshold value, for the sum of the differences of the previous and current eigenvector values. In our present research we used eigenvector centrality considering as weight both the physical distance (shortest route) and the weighted distance expressed as a product between physical distance and the number of incoming population. By definition higher eigenvector centrality values mean higher influence for a node. In our case, as the weights represent costs and not benefits, smaller cost (distances) are better, the interpretation of eigenvector values is opposite - lower eigenvector values are more desirable.

\subsection{Data sources and preprocessing}

In our study the data acquisition and preprocessing was made in QGIS, and the accessibility analysis was made on a network model because it is one of the most suitable way to model spatial relations (Bobková, 2017). As we made our research for two different time periods we have to get map date for both of it.

In case of the beginning of the $20^{\text {th }}$ century we used the map sheets of the AustroHungarian Empire, which scale varied between 250.000 to 400.000 . The map sheets were georeferenced using the Bessel ellipsoid parameters. Two thematic layers were digitized from them: the settlement and the road network layer. The non-spatial data regarding the population number of that time was collected from statistical records of the 1910 census digitally prepared and made publicly available by Varga E. Árpád (1992).

Unfortunately, the version of the database management application used by UNESCO in which the digital census data is freely available, has several inconvenient. It is an application that cannot be run on current 64-bit operating systems, it uses a custom data format and has limited export capabilities. To regain the data recorded in this format was a challenge in itself. It was necessary to install an old, unsupported 32-bit version of Windows XP, and it was necessary to search for a full version of WINISIS because the version downloaded from the website did not have the proper export capability. After resolving the situation, the database was converted to Excel format and based on settlement's name it was joined with the locations on the map.

In case of the nowadays data, the road network was obtained from OpenStreetMaps, the settlement location from geo-spatial.org portal, which made publicly available different vector data including Romania's cities position, while the data source for population data of 2011 census was the National Statistical Institute of Romania. 
The main reason for choosing OSM is that raw data can be downloaded, while for proprietary maps (Microsoft Bing Maps, Google Maps, Here Technologies Here WeGo etc.) only the analysis results can be obtained freely (ex. shortest routes). OpenStretMaps data being a Volunteered Geographic Information (VGI) it's normal to check the data accuracy. Fortunately, there are studies about this issue testing the data accuracy from China (Wang et al, 2013) through Turkey (Hacar et al., 2018) and Germany (Helbich et al, 2012) to Great Britain (Haklay, 2010) and Ireland (Ciepłuch et al, 2010). Hacar and collaborators emphasizes how the volunteers experience level determines the accuracy. In case of China the position data accuracy proved to be very poor especially for low level roads. The situation is much better in Europe where position imprecision varies a few meters, mentioning that high accuracy is mainly present in highly populated urban centers.

Both for the beginning of $20^{\text {th }}$ century and for nowadays the points representing the settlements were connected with the road network by direct connections and a graph based network model was created. In that model some of the nodes are representing the crossroads while others the settlements. Each road segment between different node pairs had the length attribute and each node that represents a settlement had the population number, resulting a node and edge weighted network model for further analysis.

\section{RESULTS AND DISCUSSION}

Calculating the polygon scale index, we defined the theoretical possibility for every county to could have a well (centrally) positioned center, as for circle like forms it's more easy to have a highly accessibile center than for elongated or irregular shapes.

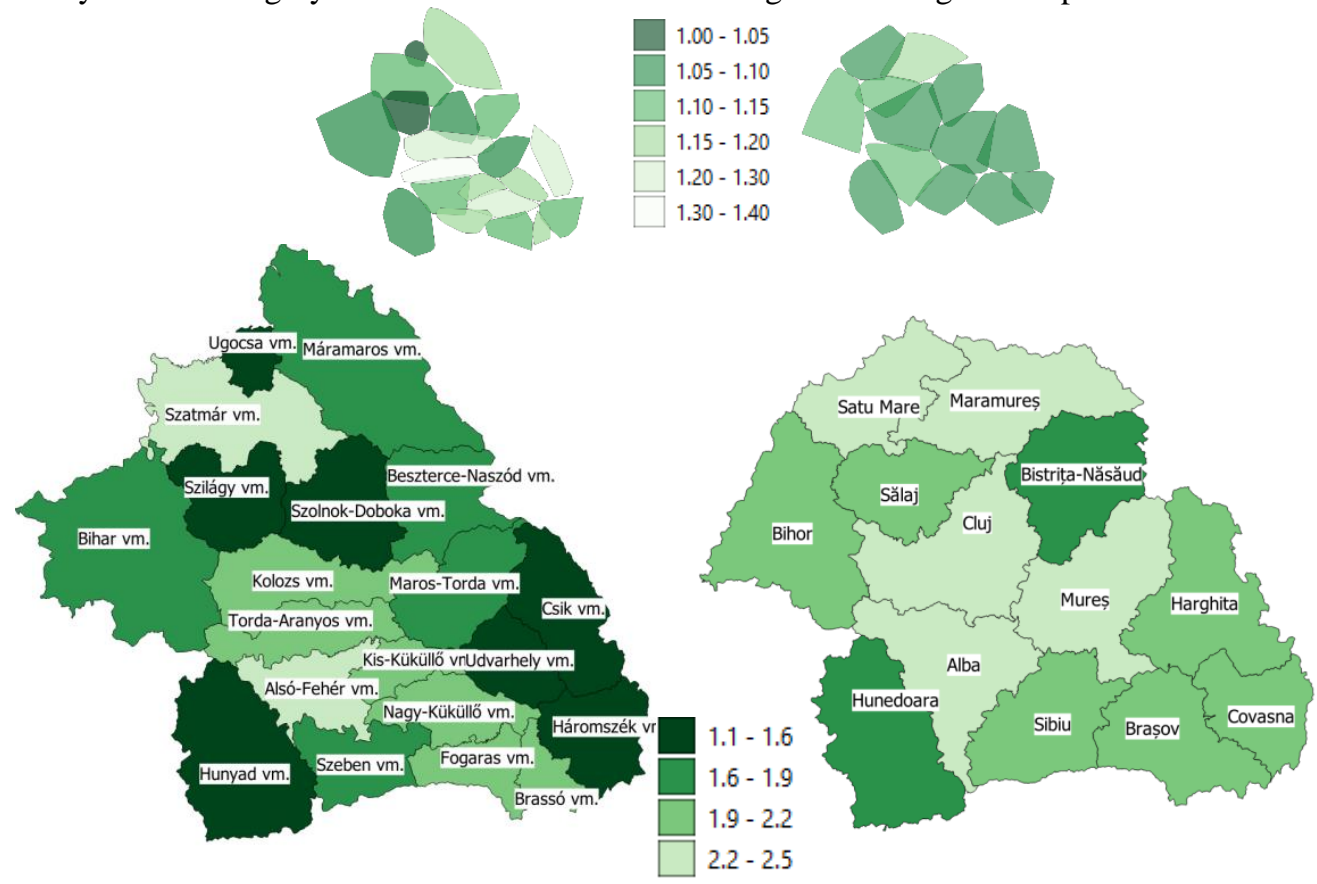

Fig. 1. County shape index at present (right) and past (left) with actual border and settlement defined hull polygons (upper maps). 
Using the same legend category, it was unexpected to see, that administrative entities from the beginning of the $20^{\text {th }}$ century are most suitable to create centrally positioned centers then the current administrative units.

We identified that the vectorization scale for the two cases could have influence on the results as the perimeter of shapes depends more on vectorization detail than the area. To overcame this difference, we created convex hull polygons for both time moments for each county based on their settlements (Fig. 1). Calculating the scale index for these newly created hull polygons the results seems to model more accurate the situations. For nowadays the distribution of scale index is more balanced, having middle to high values for most of the actual counties. For the beginning of $20^{\text {th }}$ century the scale index distribution has a wider range with two counties in the best scale index range, but also four counties in the two worst value range, using the same legend category for both cases.

In conclusion the current administrative boundaries offer a better theoretical positioning for county centers to have an excellent accessibility. This is proved also by the average values of the shape index for the hull polygons. The relative standard deviation for the counties existing at the beginning of the $20^{\text {th }}$ century is 0.069 , while for actual situation is only 0.022 .

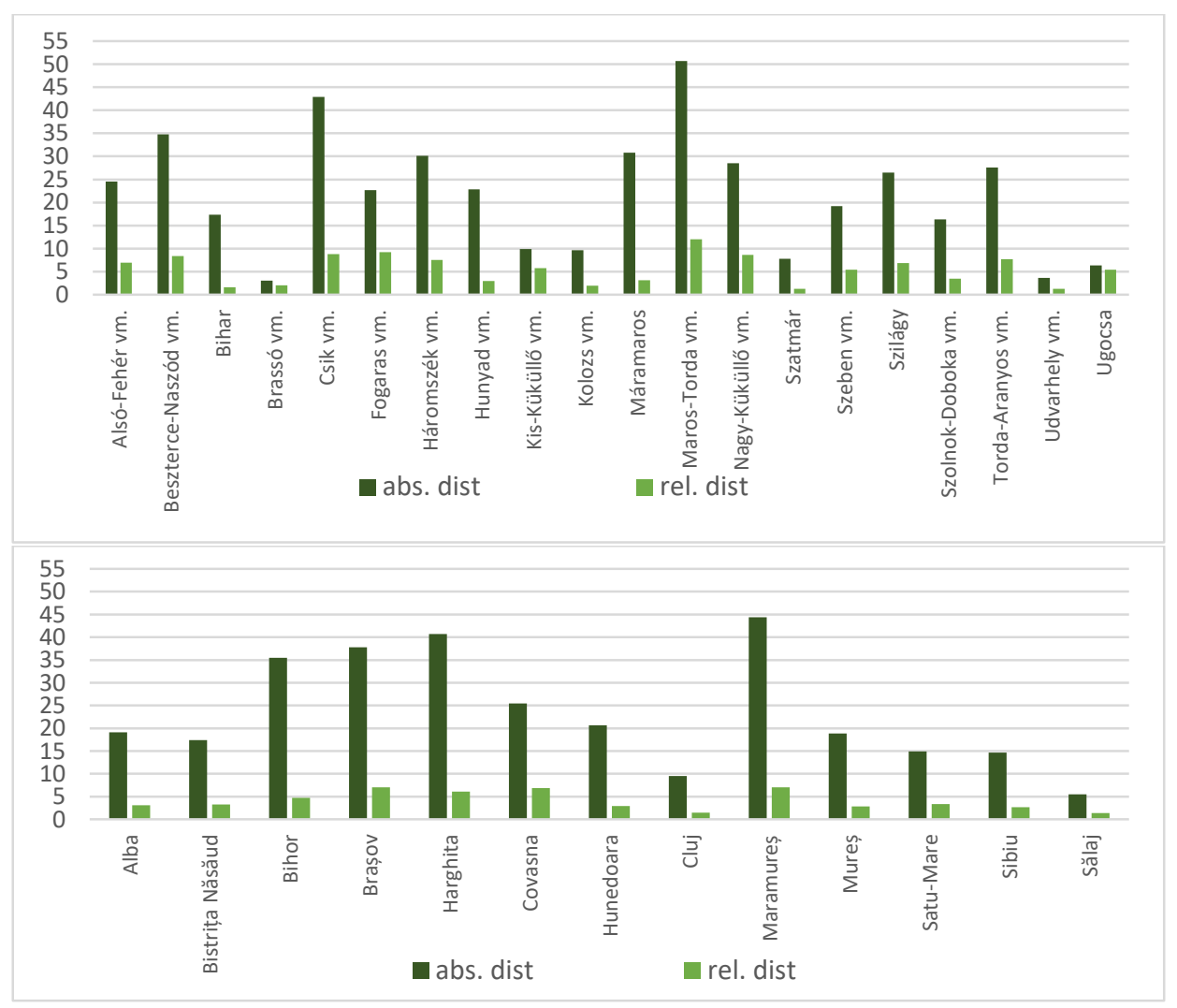

Fig. 2. Distances between polygon centroids and county center. 
We continued with measuring the distance between the polygons' centroids and the actual county centers. The raw values are similar for the two time moments with a slightly higher average distance for actual time but also with a lower standard deviation. To have a more precise representation we calculated the relative distance against the area of the polygons, because it's normal to have higher values for larger areas and the actual counties area are much higher than the counties in the beginning of the $20^{\text {th }}$ century (Fig. 2). The mentioned relative distance improved both calculated indicators: the average of the relative distance with $20 \%$, the standard deviation with $31 \%$ for current time. Even if the current counties have larger areas then those at the beginning of the $20^{\text {th }}$ century, their county centers are relatively closer to the polygon centroids and by this they have a better location potential to fulfill their central role.

Till now the analysis' regarded the counties having a continuous space with free movement inside them, in the following the road network was considered to measure the accessibility. For that we have calculated the closeness centrality for each settlement inside the county that belongs to. This value indicates for every settlement how suitable is to be the county center. We performed this centrality analysis both in not weighted and weighted form. We considered as weight the number of population in the settlements.

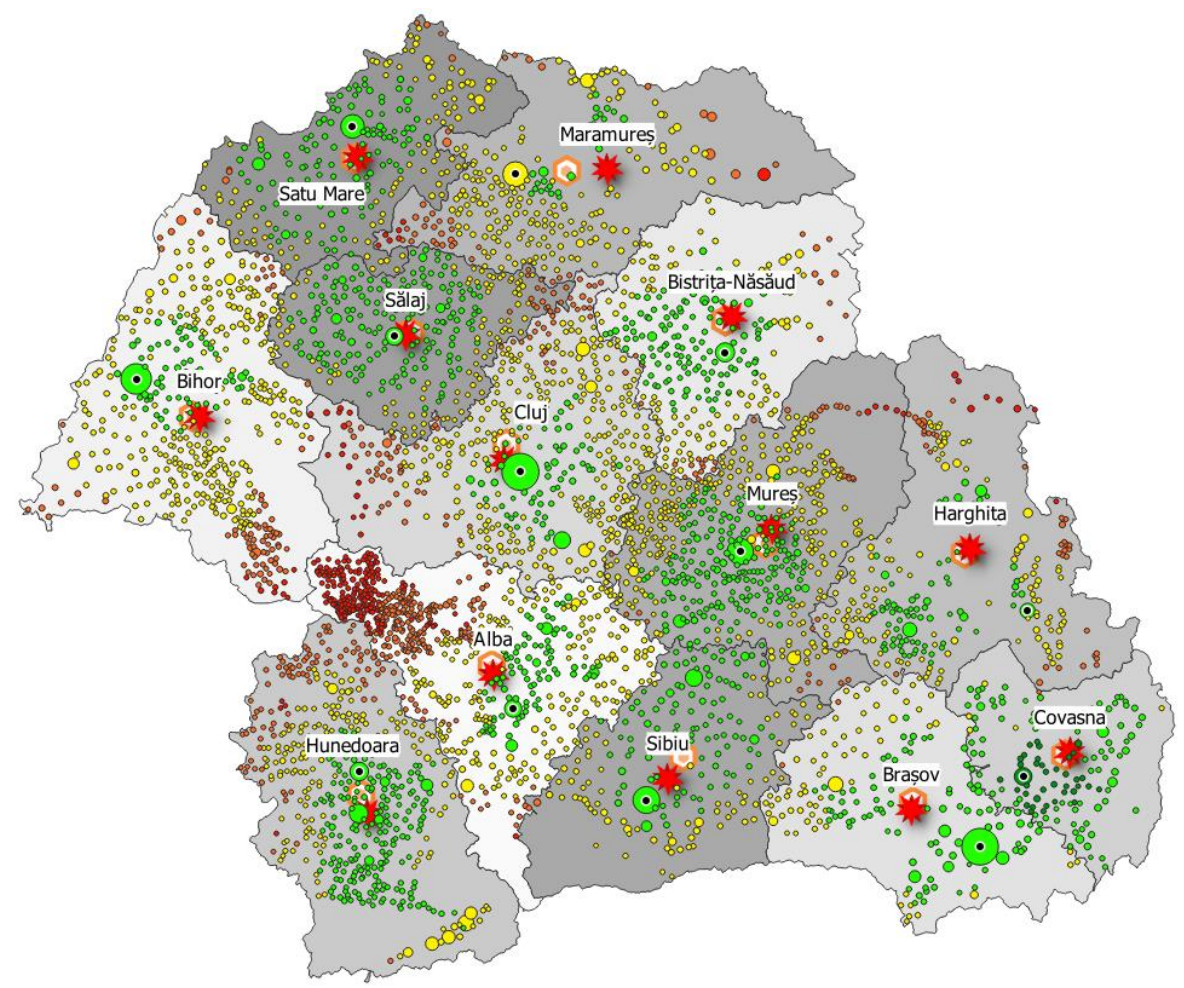

Fig. 3. Settlements' accessibility measured as weighted closeness centrality. County centers are marked with black points, the circles' area is proportional with their population, the red starts mark the county polygon's center and the orange hexagon the hull polygons' center. The colors indicate the suitability category for each settlement to became county center in terms of accessibility (green to red - higher to lower). 
To make a proper modeling in every analysis we considered that the currently analyzed settlement (for which we are calculating the closeness centrality) has the population of the current county center's population by temporary swapping their population number. Without this consideration we could not have a realistic modeling, as due to the important population number in county centers just the nearby settlements could candidate to the county center role.

Even if the graphical representation is picturesque (Fig. 3) it could not provide all details, we summarized the important results in Table 1. The candidate settlements were selected based on their population number. Just those settlements are mentioned which has at least 10.000 inhabitants. There are some very clear situations.

In case of Bihor, Cluj, Mureș and Satu-Mare the county centers are really best positioned, in some other cases the situation maybe doesn't seem ideal but in reality it's very good, with no mentionable alternatives such as Brașov, Covasna, Sălaj. Based on the results we think that for Harghita and Hunedoara neither by structural nor by practical point of view we cannot say that the actual county centers are the best choices, of course just regarding the accessibility.

Ranking of actual city centers based on closeness centrality

Table 1. and proposed alternative county centers.

\begin{tabular}{|l|c|c|c|c|}
\hline \multicolumn{1}{|c|}{ County name } & $\mathbf{R}_{\mathbf{c c}}$ & $\mathbf{R}_{\text {wcc }}$ & $\mathbf{C S}_{\mathbf{c c}}$ & $\mathbf{C S}_{\text {wcc }}$ \\
\hline Alba & 3 & 10 & - & - \\
\hline Bihor & 1 & 1 & - & - \\
\hline Bistrița-Năsăud & 7 & 25 & - & Năsăud [18], Beclean [21] \\
\hline Brașov & 2 & 8 & - & - \\
\hline Covasna & 1 & 8 & - & - \\
\hline Cluj & 1 & 1 & - & Odorheiu \\
\hline Harghita & 13 & 68 & Secuiesc [3] & $\begin{array}{c}\text { Odorheiu Secuiesc [23], } \\
\text { Gheorgheni [63] }\end{array}$ \\
\hline Hunedoara & 7 & 80 & Simeria [4] & $\begin{array}{c}\text { Călan [3], Hațeg [20], } \\
\text { Hunedoara [34], Simeria [49] }\end{array}$ \\
\hline Maramureș & 1 & 35 & - & Baia Sprie [22] \\
\hline Mureș & 1 & 1 & - & - \\
\hline Sălaj & 2 & 3 & - & - \\
\hline Satu Mare & 2 & 1 & - & Mediaș [33] \\
\hline Sibiu & 1 & 45 & - & count center's rank \\
\hline
\end{tabular}

$R_{c c}$ - actual county center's rank in closeness centrality measure / $R_{w c c}$ - actual county center's rank in weighted closeness centrality measure $C S_{c c}$ - candidate settlements from closeness centrality values $C S_{w c c}$ - candidate settlements from weighted closeness centrality values. Values in brackets indicates settlement ranking for candidate cities.

Calculating the eigenvector centrality both in unweighted and weighted way we got the values indicating the influence of every settlement in the network. The results are presented in Table 2 which in main part matches with the situation based on closeness centrality: Mureș, Cluj and Satu-Mare are clearly the winners, while Hunedoara and Harghita are laggards.

For those settlements who were marked as candidate for the county center role we have remade the weighted closeness centrality and weighted eigenvector centrality analysis, 
considering those settlements as county centers but keeping their population number. We want to see whether in this case their weighted centrality and weighted eigenvector centrality will have better values that the actual county centers.

The obtained result can be summarized as follows: in case of Sălaj county Jibou would not be a viable county center. In case of Sibiu county Mediaș would not be a better choice in terms of weighted closeness centrality, having a worst relative rank, although its ranked higher than Sibiu. The best solution for Bistrița Năsăud county would be to have Beclean as county center if we look just at the weighted closeness centrality. In this case also Năsăud city would have a higher rank than in actual situation. For Hunedoara county the best case would be to have Călan as county center, for Maramureș county with the city of Baia Sprie being county center would have higher accessibility. In case of Brașov county the city of Codlea it could be a viable alternative as county center, and in case of Harghita county Odorheiu Secuiesc could take the place of Miercurea Ciuc.

If we consider the distances between alternative and actual city centers just in two cases the theoretical change of county center would produce significant changes, as in case of Sibiu and Harghita county the distance exceeds 50km.

Table 2.

Ranking of actual city centers based on eigenvector centrality and proposed alternative county centers.

\begin{tabular}{|l|c|c|c|c|}
\hline \multicolumn{1}{|c|}{ County name } & $\mathbf{R}_{\text {ec }}$ & $\mathbf{R}_{\text {wec }}$ & $\mathbf{C S}_{\text {ec }}$ & $\mathbf{C S}_{\text {wec }}$ \\
\hline Alba & 172 & 1 & - & - \\
\hline Bihor & 6 & 1 & - & - \\
\hline Bistrița-Năsăud & 4 & 4 & - & - \\
\hline Brașov & 82 & 17 & $\begin{array}{c}\text { Făgăraș [13], } \\
\text { Codlea [42] }\end{array}$ & - \\
\hline Covasna & 13 & 19 & - & Gheorgheni [29] \\
\hline Cluj & 1 & 1 & - & Călan [6], Hațeg [11], \\
\hline Harghita & 25 & 31 & $\begin{array}{c}\text { Odorheiu } \\
\text { Secuiesc [3] }\end{array}$ & Hunedoara [37], Simeria [57] \\
\hline Hunedoara & 3 & 93 & - & Baia Sprie [40] \\
\hline Maramureș & 13 & 68 & Baia Sprie [9] & - \\
\hline Mureș & 1 & 1 & - & - \\
\hline Sălaj & 9 & 3 & Jibou [4] & - \\
\hline Satu Mare & 1 & 1 & - & - \\
\hline Sibiu & 2 & 5 & - & - \\
\hline
\end{tabular}

$R_{e c}$ - actual county center's rank in eigenvector centrality measure $/ R_{\text {wec }}$ - actual county center's rank in weighted eigenvector centrality measure $C_{e c}$ - candidate settlements from eigenvector centrality values $C S_{\text {wec }}$ - candidate settlements from weighted eigenvector centrality values. Values in brackets indicates settlement ranking for candidate cities. Values in brackets indicates settlement ranking for candidate cities.

As mentioned our research want to compare the actual situation with that of 100 years ago. The direct comparison is practically impossible as the county boundaries have changed. We perform the analysis for those cities which were county centers even 100 years ago to see how imposing they were at that time. For this analysis we considered as alternative county centers those cities which had at least 3.000 inhabitants at that time. 
Looking at Table 3 and Table 4 we can notice that in several cases the situation was the same: Oradea as county center for Bihor/Bihar, Sfântu Gheorghe as county center for Covasna/Háromszék, Cluj-Napoca as county center for Cluj/Kolozsvár and Satu Mare for Satu Mare/Szatmár had the best accessibility and influence inside their (changed) counties. On the other side Miercurea-Ciuc and Deva had a not very clear position even 100 years ago. Târgu Mureș through time enforced a little it's accessibility to nowadays while Bistrița and Braşov had a little bit better accessibility in the past.

Table 3.

Ranking of cities which are historically county centers based on closeness centrality and proposed alternative county centers based on data from the beginning of $20^{\text {th }}$ century.

\begin{tabular}{|l|c|c|c|c|}
\hline $\begin{array}{c}\text { County center } \\
\text { name }\end{array}$ & $\mathbf{R}_{\mathbf{c c}}$ & $\mathbf{R}_{\text {wcc }}$ & $\mathbf{C S}_{\mathbf{c c}}$ & $\mathbf{C S}_{\text {wcc }}$ \\
\hline Bistrița & 1 & 1 & - & - \\
\hline Oradea & 1 & 1 & - & - \\
\hline Brașov & 1 & 2 & - & Sândominic [5] \\
\hline Miercurea Ciuc & 7 & 27 & - & - \\
\hline Sfântu Gheorghe & 9 & 13 & - & Hunedoara [9] \\
\hline Deva & 9 & 25 & - & - \\
\hline Cluj-Napoca & 4 & 4 & - & - \\
\hline Târgu Mureș & 1 & 2 & - & Selistea [9] \\
\hline Satu Mare & 1 & 1 & - & Simleu Silvaniei [14] \\
\hline Sibiu & 2 & 18 & - & \\
\hline Zalău & 19 & 21 & Simleu Silvaniei [16] & \\
\hline
\end{tabular}

Table 4.

Ranking of cities which are historically county centers based on eigenvector centrality and proposed alternative county centers based on data from the beginning of $20^{\text {th }}$ century.

\begin{tabular}{|l|c|c|c|c|}
\hline $\begin{array}{c}\text { County center } \\
\text { name }\end{array}$ & $\mathbf{R}_{\mathbf{e c}}$ & $\mathbf{R}_{\text {wec }}$ & $\mathbf{C S}_{\mathbf{e c}}$ & $\mathbf{C S}_{\text {wec }}$ \\
\hline Bistrița & 1 & 2 & - & - \\
\hline Oradea & 1 & 1 & - & - \\
\hline Brașov & 1 & 1 & - & - \\
\hline Miercurea Ciuc & 13 & 25 & Frumoasa [12] & $\begin{array}{c}\text { Sândominic [5], Joseni [18], } \\
\text { Frumoasa [21], Gheorgheni [24] }\end{array}$ \\
\hline Sfântu Gheorghe & 22 & 26 & - & - \\
\hline Deva & 11 & 29 & Hunedoara [5] & Hunedoara [3] \\
\hline Cluj-Napoca & 1 & 1 & - & Reghin [5] \\
\hline Târgu Mureș & 23 & 24 & Reghin [5] & - \\
\hline Satu Mare & 1 & 1 & - & Selistea [9] \\
\hline Sibiu & 3 & 13 & - & - \\
\hline Zalău & 15 & 17 & - & \\
\hline
\end{tabular}




\section{CONCLUSIONS}

The presented research wanted to characterize how accessible were and are the county centers for several Romania's counties. For evaluation two approaches were used, the shape index and two centrality measures: closeness and eigenvector centralities in unweighted and weighted variants. We have found that the shape index representing the centrality potential for counties has no relation with actual road network based accessibility. The correlation values between shape index and centrality values are far below a considerable value.

The role of county centers inside their counties, measured as accessibility values are not so different through 100 years even if the administrative boundaries has changed, sometimes substantially. Most of county centers has an excellent or good accessibility and influence and even if some's accessibility is just acceptable, the obtained alternatives would not produce important changes. In these cases, using the actual road network a significantly better location could not be found. This appreciation is valid for past and present. In the study we identified two counties where the change of the county centers it would make sense in terms of accessibility.

Through our research we proved that there are cases when historical, cultural or other arguments may prevail over a practical aspect, expressed in this case with centrality.

Acknowledgements. The presented research was supported by the DOMUS scholarship program of the Hungarian Academy of Sciences.

\section{REFERENCES}

Bennison, D.J. (2010), The measurement of settlement centrality, The Professional Geographer, 30(4), 371-376

Bilașco, S., Roșca, S., Păcurar, I., Moldovan , N., Vescan, I., Fodorean, I., Petrea, D. (2018), Roads accessibility to agricultural crops using GIS technology. Methodological approach., Geographia Technica, 13(2), 12-30

Bobková, M., Holesinka, A. (2017), Networking in a destination from the perspective of virtual relationships and their spatial dimension, Geographia Technica, 12(2), 10-19

Ciepłuch, B., Jacob, R., Mooney, P., Winstanley, A.C. (2010), Comparison of the accuracy of OpenStreetMap for Ireland with Google Maps and Bing Maps, Proceedings of the Ninth International Symposium on Spatial Accuracy Assessment in Natural Resources and Environmental Sciences 20-23rd July 2010. p. 337.

Dijkstra, E.W. (1959). A note on two problems in connexion with graphs, Numerische Mathematik, 1, 269-271.

Frohn, R.C. (1998) Remote Sensing of Landscape Ecology: New Metric Indicators of Monitoring, Modeling and Assessing of Ecosystems. Lewis Publishers, Boca Raton, Florida.

Hacar, M., Kilic, B., Shabaz, K. (2018), Analyzing OpenStreetMap Road Data and Characterizing the Behavior of Contributors in Ankara, Turkey, International Journal of Geo-Information, 7, 1-12

Haklay, M. (2010), How good is Volunteered Geographic Information? A comparative study of OpenStreetMap and Ordnance Survey Dataset, Environment and Planning B: Urban Analytics and City Science, 37(4), 682-703 
Helbich, M., Amelunxen, C., Neis, P., Zipf, A. (2012), Comparative Spatial Analysis of Positional Accuracy of OpenStreetMap and Proprietary Geodata, in Jekel, T., Car, A., Strobl, J. \& Griesebner, G. (Eds.): GI_Forum 2012: Geovizualisation, Society and Learning, 24-33

Hellervik, A., Nilsson, L., Andersson, C. (2019), Preferencial centrality - A new measure unifying urban activity, attraction and accessibility, Environment and Planning B Urban Analytics and City Sciences, 46, 1331-1346

Hexmoor, H. (2015), Network Analysis, in Computational Network Science, 15-19

Kang, C-D (2015), The effects of spatial accessibility and centrality to land use on walking in Seoul, Korea, Cities, 46, 94-103

Lang, S., Blaschke, T. (2007) Landschaftsanalyse mit GIS, Eugen Ulmer Stuttgart

Miller, E.J. (2018), Accessibility: measurement and application in transportation planning, Transport Reviews, 38(5), 551-555

Negre, C.F.A, Morzan, U.N., Hendrickson, H.P., Pal, R., Lisi, G.P., Loria, J.P., Rivalta, I., Ho, J., Batista, V.S. (2018). Eigenvector centrality for characterization of protein allosteric pathways, Proceedings of the National Academy of Sciences, 115(52), 12201-12208.

Nicoara, P-S. \& Haidu, I. (2014) A GIS based network analysis for the identification of shortest route access to emergency medical facilities. Geographia Technica, 9(2), 60-67.

Patton, D.R. (1975). A diversity index for quantifying habitat 'edge'. Wildlife Society Bulletin, 3, 171173.

Rodrigue, J-P et al. (2017) The Geography of Transport Systems, Hofstra University, Department of Global Studies \& Geography, https://transportgeography.org

Sabidussi, G (1966). The centrality index of a graph, Psychometrika, 31(4), 581-603.

Schumaker, N.H. (1996) Using landscape indices to predict habitat connectivity. Ecology, 77, 12101225.

Varga E.A. (1992), Népszámlálások a jelenkori Erdély területén, Regio-MTA Történettudományi Intézet, Budapest, 214 